\title{
Finite Element Analysis of Symmetric and Asymmetric Three-roll Rolling Process
}

\author{
Pesin A. ${ }^{1, \mathrm{a}}$, Chukin M. ${ }^{1, \mathrm{~b}}$, Pustovoytov D. ${ }^{1, \mathrm{c}}$ \\ ${ }^{I}$ Nosov Magnitogorsk State Technical University, \\ 38, Lenin prospect, Magnitogorsk, 455000, Russia
}

\begin{abstract}
A three-roll process is a significant technique in the production of wire rod, round bars and hexagonal profiles for structural applications. Better mechanical properties of wire rod, round bars and hexagonal profiles can be achieved due to large plastic deformation by the three-roll process. Asymmetric rolling is a novel technique characterised by a kinematic asymmetry linked to the difference in peripheral speed of the rolls, able to introduce additional shear strains through the bar thickness. In order to achieve this, asymmetrical three-roll rolling process was investigated to better control the deformation compared to the conventional three-roll rolling process in a stand with two three-roll calibers located very close to each other. Simulation of round-triangle-triangle pass rolling was performed. FEM simulations were carried out with using software DEFORM 3D. The influence of the friction coefficient and speed asymmetry on the shear strain and material flow was discussed. The results of simulation can be used to optimize the asymmetric three-roll rolling process to improve the mechanical properties of wire rod, round bars and hexagonal profiles.
\end{abstract}

\section{Introduction}

A three-roll rolling process is a significant technique in the production of wire rod, round bars and hexagonal profiles for structural applications. It is a rolling process in which material is shaped by three rolls in three directions, everyone of which is inclined to the others at $120^{\circ}[1,2]$. Three-roll rolling process has various advantages such as easy flow control, small space requirement, and comparatively uniform deformation, etc. The restriction of the material imposed by the shape of caliber rolls in the three-roll rolling process is greater than that in the two-roll rolling process. The accuracy of the shape of products made by the three-roll rolling process is considered to be higher than that of the two-roll rolling process [1-3].

It is well known that efficient way to increase strength of metallic materials is to form an ultra-fine grain structure using severe plastic deformation (SPD) methods [4]. Many different SPD processes have been developed to date. One of the most advanced methods of SPD for manufacturing of long ultrafine-grained metal products is the asymmetric rolling process based on the purposefully generated asymmetry due to difference between the peripheral speeds or diameters of the work rolls [5-7]. Asymmetrical rolling with different peripheral speeds is more available for industrial application.

Better mechanical properties of wire rod, round bars and hexagonal profiles can be achieved due to large plastic deformation in asymmetrical three-roll rolling process. In asymmetric rolling, the rolling force of the process is greatly reduced in comparison to that of conventional rolling. Reduction of rolling force has a major advantage that very large strains can be imparted into the material for producing ultra-fine grain structures, modification of textures and production of high strength materials. Asymmetric rolling results in the development of strain with strong shear components, both at the surfaces and at the center of the workpiece.

Many works studied the shear strain during asymmetrical two-roll rolling process by using finite element method. Ji et al. [8] investigated deformation mechanics of differential-speed rolling with a high-speed ratio between the rolls by rigid-plastic FEM. It was found out that the shear strain takes a great portion of the total effective strain $(\sim 3.5)$ in average. Ji and Park [6] analyzed various asymmetric rolling processes by the rigid-viscoplastic FEM. The results of the numerical simulation demonstrated that shear strain is more severe in the material layers, where the peripheral speed or friction coefficient is greater. Kim et al. [9] analyzed the effect of speed ratio on the development of shear strain and texture during differential speed rolling. FEM simulation results showed that the effective strain accumulated during asymmetric rolling increased with high-speed ratio.

A new method of asymmetrical three-roll rolling process was suggested in [10]. On the basis of the finite element simulation it was stated that with reduction

$\overline{\text { apesin@bk.ru (corresponding author), }}{ }^{\mathrm{b}} \mathrm{m} . \mathrm{chukin@mail.ru,}{ }^{\mathrm{c}}$ pustovoitov_den@mail.ru 
ratio of $41.2 \%$ in the course of increase of speed asymmetry coefficient up to 1.7 and along with the friction coefficient increase from 0.12 up to 0.36 the shear angle grows up to $48^{\circ}$. Research of influence of different technological factors on metal elongation, shear strain and strain effective in a single three-roll caliber was performed in [11]. One of the problems of asymmetrical three-roll rolling is bending of the bar at the exit from the deformation zone what makes its threading into the next pass more difficult. The solution of this problem can be done with using asymmetrical three-roll rolling process in a stand with two three-roll calibers located very close to each other [12].

The goal of this research is to determine and to compare the effective strain and the shear strain during symmetric and asymmetric three-roll rolling process in a stand with two three-roll calibers located very close to each other. The influence of the friction coefficient and speed asymmetry on the shear strain and material flow was discussed.

\section{Research method}

Commercial software DEFORM 3D, based on finite element method, was used to analyze symmetrical and asymmetrical three-roll rolling process. The three-roll rolling process in a stand with two three-roll calibers located very close to each other was performed (Fig. 1). The shape of the first and the second calibers was triangle. The initial shape of the bar was a round and the final shape was a hexagonal (Fig. 2). A round bar of $\mathrm{d}=8.0 \mathrm{~mm}$ diameter of AISI 1010 was used. The radius of rolls was $\mathrm{R}=140 \mathrm{~mm}$. The three-roll rolling process was performed without front and back tensions. Coulomb friction law was used. The friction coefficient $\mu$ varied within the range of $0.06 \ldots 0.36$. In the course of simulation, the following assumptions were made: 1) deformed medium - hardened rigid-plastic material; 2) work rolls - absolutely rigid; 3) conditions of deformation - isothermal. To approximate the geometric parameters of the bar, tetrahedral elements were used. Peripheral speeds of the rolls were set according to the relationship (1). Peripheral speed of the first roll in all calculation variants was set constant $\left(\mathrm{V}_{1}\right.$ $=1.0 \mathrm{~m} / \mathrm{sec}$ ).

$\mathrm{V}_{2}=\mathrm{V}_{3}=\mathrm{V}_{4}=\mathrm{V}_{5}=\frac{\mathrm{S}_{0}}{\mathrm{~S}_{1}} \mathrm{~V}_{1}, \quad \mathrm{~V}_{6}=\frac{\mathrm{S}_{0}}{\mathrm{~S}_{2}} \mathrm{~V}_{1}$

where $V_{1} \ldots V_{6}$ - peripheral speeds of the rolls; $\mathrm{S}_{0}$ - the initial cross section area of the bar; $\mathrm{S}_{1}-$ the cross section area of the bar after the first three-roll pass; $\mathrm{S}_{2}$ - the cross section area of the bar after the second three-roll pass.

The three-roll rolling process was carried out with different elongation ratio per pass: $\mathrm{S}_{0} / \mathrm{S}_{1}=1.12 \ldots 1.40$; $\mathrm{S}_{0} / \mathrm{S}_{2}=1.28 \ldots 2.00$. Speed asymmetry of the work rolls was equal to elongation of the bar material.
At the indicated conditions (1) in the contact areas between the workpiece and rolls 2, 3 and 6 the backward slip zones gets longer where the direction of tangential friction forces is along the workpiece movement. In its turn in the contact areas between the workpiece and rolls 1, 4 and 5 the forward slip zones gets longer where the direction of tangential friction forces is opposite the workpiece movement. Thus in the deformation zones the oppositely directed tangential friction forces generate additional shear strains with shear angle $\varphi$ (Fig. 3). The tangent of this angle is the characteristic of shear strain.
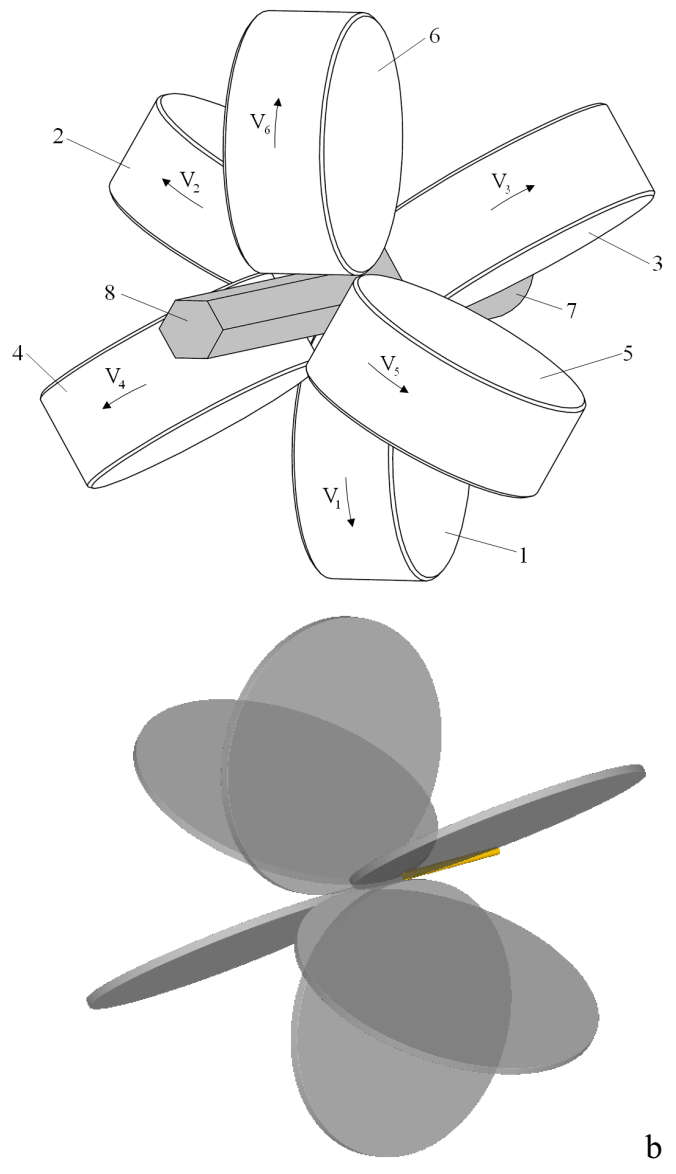

a

b

Figure 1. The scheme of the three-roll rolling process (a) and the FE model

1, 2, 3 - work rolls of the first three-roll caliber; 4, 5, 6 - work rolls of the second three-roll caliber; 7 - initial round bar; 8 - final hexagonal bar; $\mathrm{V}_{1}-\mathrm{V}_{6}$ - peripheral speeds of the rolls

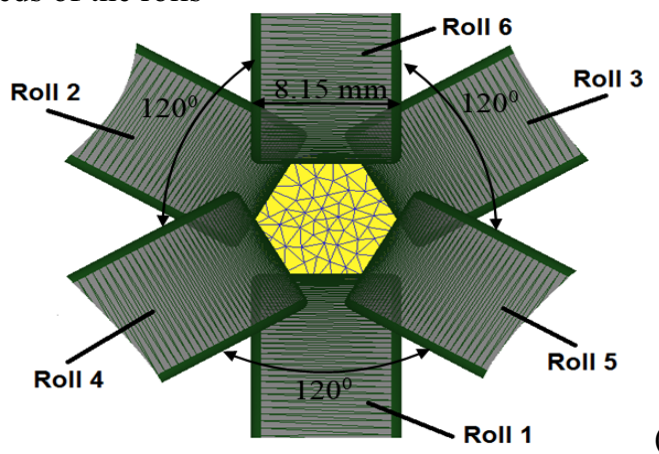




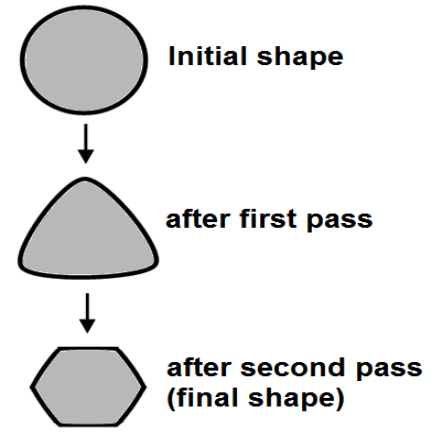

(b)

Figure 2. Arrangement of the rolls (a) and the pass schedule (b)

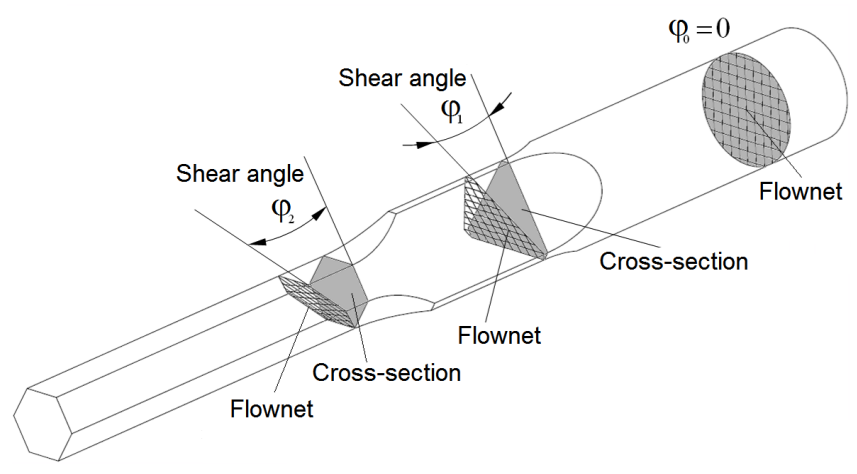

Figure 3. Schematic illustration of shear angle during asymmetrical three-roll rolling process

In the course of simulation of symmetric and asymmetric three-roll rolling process, the influence of the friction coefficient and speed asymmetry on the shear strain and material flow was studied.

\section{Simulation results and discussion}

Simulation of round-triangle-triangle pass rolling was performed. In other words, the initial material shape in the cross section was round, the first caliber shape was triangle and the second caliber shape was inverted triangle. Therefore, the final shape of the bar was a hexagonal. Three-roll calibers were located very close to each other. The distance between the first and the second plastic zones was about $55 \mathrm{~mm}$ (Fig. 4). The process was stable in all calculation variants. Fig. 5 shows the distribution of the strain effective in the cross-section of the rolled bar during symmetrical and asymmetrical three-roll rolling process. It can be inferred that the strain is smaller during symmetrical rolling. Deformation of the bar during cold asymmetrical rolling provides very high additional shear strains resulting from the high friction between the rolls and the workpiece. In Fig. 6 it is shown the flownet and shear angle for different rolling processes. It was obtained, when total elongation is $\sim 2.0$ (i.e.
$\mathrm{S}_{0} / \mathrm{S}_{2}=2.0$ ) and friction coefficient is 0.36 then shear angle $\varphi$ is about 45 degrees.

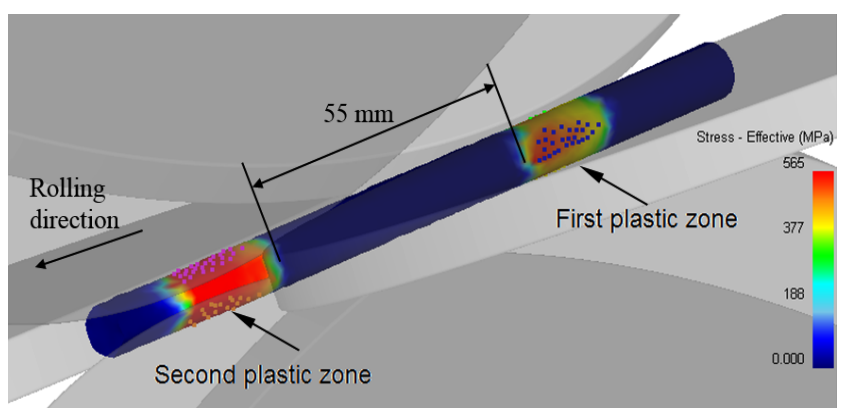

Figure 4. Stress effective field of the rolled bar during FEM simulation of asymmetrical three-roll rolling process in a stand with two three-roll calibers located very close to each other $(\mathrm{S} 0 / \mathrm{S} 1=1.14 ; \mathrm{S} 0 / \mathrm{S} 2=1.28 ;=0$. $)$
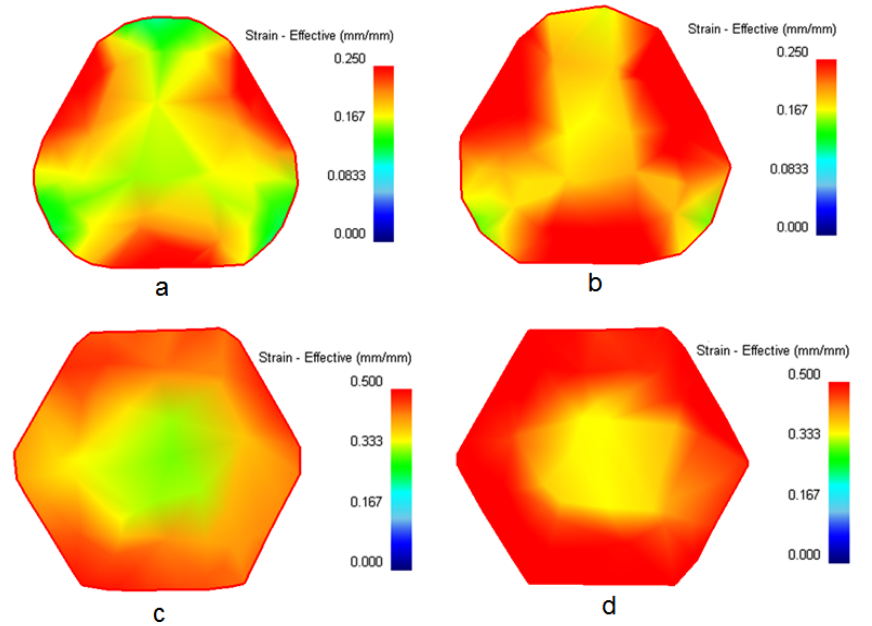

Figure 5. Strain effective field on the cross section of the rolled bar after symmetrical $(\mathrm{a}, \mathrm{c})$ and asymmetrical $(\mathrm{b}, \mathrm{d})$ three-roll rolling process $(\mathrm{S} 0 / \mathrm{S} 1=1.14 ; \mathrm{S} 0 / \mathrm{S} 2=1.28 ;=0$.)

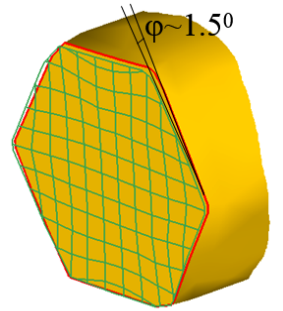

a b

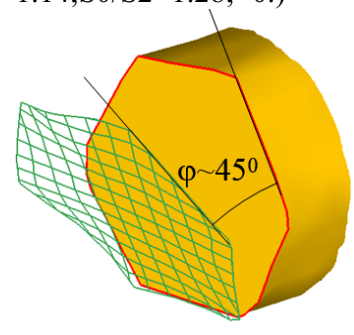

Figure 6. Shear angle j after symmetrical (a) and asymmetrical (b) three-roll rolling process $(\mathrm{S} 0 / \mathrm{S} 1=1.39$; $\mathrm{S} 0 / \mathrm{S} 2=2.00 ; \mathrm{m}=0$.)

Diagram (Fig. 7) shows the interrelation of shear angle $\varphi$ and friction coefficient $\mu$ during symmetrical and asymmetrical three-roll rolling process in a stand with two three-roll calibers located very close to each other. By analyzing the results of simulation it can be inferred that the shear angle and the shear strain are very small during symmetrical rolling. If the friction coefficient is very high (for example, 0.36 ), but the total elongation is small $\left(\mathrm{S}_{0} / \mathrm{S}_{2}=1.28\right)$ then the shear angle and the shear strain are very small during asymmetrical rolling too. 


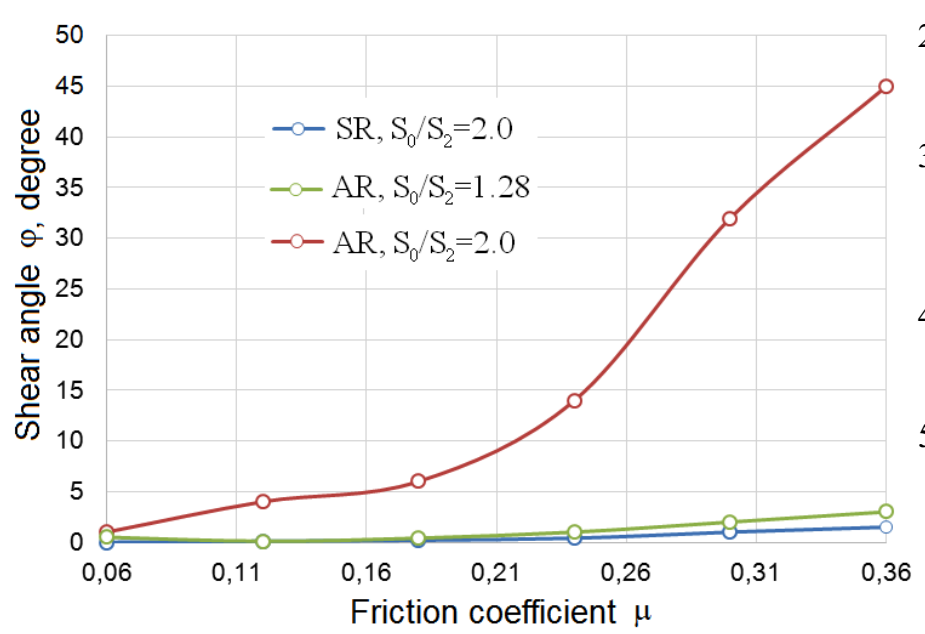

Figure 7. The interrelation of shear anglej and friction coefficientm during symmetrical (SR) and asymmetrical (AR) three-roll rolling process

\section{Conclusions}

For manufacturing of hexagonal profiles it was developed asymmetrical three-roll rolling process in a stand with two three-roll calibers located very close to each other. FE simulation of shear angle and shear strain during cold symmetrical and asymmetrical three-roll rolling process was presented in this paper. Speed asymmetry of the work rolls was equal to elongation of the bar material. When total elongation is high $\left(\mathrm{S}_{0} / \mathrm{S}_{2}=2.0\right)$ and friction coefficient is 0.36 then shear angle $\varphi$ is about 45 degrees after asymmetrical rolling. If the friction coefficient is very high, but the total elongation is small $\left(\mathrm{S}_{0} / \mathrm{S}_{2}=1.28\right)$ then the shear angle and the shear strain are very small during symmetrical and asymmetrical rolling. FE model can be used to optimize the asymmetrical three-roll rolling process to improve the microstructure and the mechanical properties of hexagonal profiles. Further experimental investigation of the asymmetrical three-roll rolling process is required.

\section{Acknowledgements}

The research work was carried out in accordance with the government order of the Ministry of Education and Science of the Russian Federation executed by Nosov Magnitogorsk State Technical University on the topic «Development of technology for manufacture of high-strength long rolled sections from materials with ultra-fine grain structure using combined processes of severe plastic deformation» (project No $11.1525 \mathrm{~K}$ from 18.07.2014)

\section{References}

1. K. Komori, Simulation of deformation and temperature in multi-pass three-roll rolling, Journal of Materials Processing Technology. 92-93 (1999) 450-457.
2. C. Overhagen, P. Mauk, A new rolling model for three-roll rolling mills, Key Engineering Materials. 622-623 (2014) 879-886.

3. J.H. Min, H.C. Kwon, Y. Lee, J.S. Woo, Y.T. Im, Analytical model for prediction of deformed shape in three-roll rolling process, Journal of Materials Processing Technology. 140 (2003) 471-477.

4. Laszlo S. Toth, Chengfan Gu, Ultrafine-grain metals by severe plastic deformation, Materials Characterization. 92 (2014) 1-14.

5. Zhiming Li, Liming Fu, Bin Fu, Aidang Shan, Effects of annealing on microstructure and mechanical properties of nano-grained titanium produced by combination of asymmetric and symmetric rolling, Materials Science and Engineering: A. 558 (2012) 309-318.

6. Y.H. Ji, J.J. Park, Development of severe plastic deformation by various asymmetric rolling processes, Materials Science and Engineering: A. 499 (2009) 14-17.

7. Kyung-Moon Lee, Hu-Chul Lee, Grain refinement and mechanical properties of asymmetrically rolled low carbon steel, Journal of Materials Processing Technology. 210 (2010) 1574-1579.

8. Ji Y.H., Park J.J., Kim W.J., Finite element analysis of severe deformation in $\mathrm{Mg}-3 \mathrm{Al}-1 \mathrm{Zn}$ sheets through differential-speed rolling with a high-speed ratio, Materials Science and Engineering A. 454-455 (2007) 570-574.

9. W.J. Kim, B.G. Hwang, M.J. Lee, Y.B. Park, Effect of speed-ratio on microstructure and mechanical properties of $\mathrm{Mg}-3 \mathrm{Al}-1 \mathrm{Zn}$ alloy, in differential speed rolling, Journal of Alloys and Compounds. 509 (2011) 8510-8517.

10. A. Pesin, M. Chukin, A. Korchunov, D. Pustovoytov, Finite element modeling of shear strain in asymmetric and symmetric rolling in multi roll calibers, Procedia Engineering 81 (2014) 2469-2474.

11. A. Pesin, M. Chukin, A. Korchunov, D. Pustovoytov, Finite element modeling of shear strain in rolling with velocity asymmetry in multi-roll calibers, Key Engineering Materials. 622-623 (2014) 912-918.

12. A. Tkachenko, A. Eremin, N. Gorkin, M. Birykov, Cassette-type stand with dual adjustable gauges for three-roll rolling of section bars, Modeling and development of metal forming processes. (2012) 237-244. 